\title{
300: Psychiatry Taught Through the Lens of Film and Natural History
}

\author{
Anthony Tobia*, MD, Christine Annibali, MD, Christopher Massa, MD, Ph.D, Marez Megalla, MD, Christopher \\ Pumill, MD, Leya Schwartz, MD, Shantel Suncar, MD, Michael Ullo, MD, Michelle Walker, MD, Roseanne \\ Dobkin, Ph.D \\ Rutgers Robert Wood Johnson Medical School, USA
}

Submission: December 29, 2016; Published: January 05, 2017

*Corresponding author: Anthony Tobia, MD, Rutgers Robert Wood Johnson Medical School, 671 Hoes Lane, USA

\begin{abstract}
Objective: Movies have long been utilized to highlight varied areas in the field of psychiatry. We have previously described a course [1] that teaches psychopathy to psychiatry residents based on the horror genre. Methods: Course directors subsequently created a medical student elective (SCREAM) that serves as a steering committee for the residents's course. As art imitates life, the primary focus of SCREAM is to enhance residents' didactics by incorporating media inspired by true stories. Such teaching not only takes advantage of the strengths of fictional case studies [1], but also appreciates that the films are often inspired by actual events. Results: This paper reviews three historical events that occurred 100 years apart and relates them to both the movies they inspired and their relevance to the field of psychiatry. Conclusions: Courses that use media to teach are found to be engaging and are an innovative way to educate future physicians. Key words: Film-Medical EducationMedia-Psychopathology
\end{abstract}

\section{Introduction}

Courses designed to teach psychopathology to trainees have traditionally used examples from art and literature to emphasize major teaching points. Reviewing [Mental] Disorders with a Reverent Understanding of the Macabre (REDRUM) is a psychopathology course at our institution that teaches topics in mental illnesses through the horror film genre [1]. With about $95 \%$ of medical students pursuing careers outside of psychiatry [2], it is imperative that innovative curricula such as REDRUM be accessible to medical students. With the high prevalence of co-occurring psychiatric disorders in the general medical population, it's likely that the $3^{\text {rd }}$-year psychiatry clerkship will be the final opportunity for future physicians to learn about the mental disorders they'll see in future practice.

Accordingly, course directors of REDRUM developed a 1-credit medical student elective to act as a steering committee for the residents's psychopathology course. The course is available to fourth-year students who satisfactorily completed their core psychiatry clerkship. The Steering Committee on Resident Education and Media (SCREAM) is directed by the Associate Program Director of residency training with the objective to enhance and evolve the residents' didactic through novel discoveries related to media such as film.

\section{Methods}

The REDRUM Psychopathology course is held weekly for one hour over one semester (about 15 weeks). The one-hour didactic is supplemented by weekly readings and film viewings that take place approximately two hours per week outside of the classroom setting. SCREAM meets monthly to discuss historical and current events in art and literature that can directly contribute to the resident curriculum. Discussions generated at each session result in course work that takes approximately two hours per week outside of the meetings. For example, with the recent success of the Showtime series, Penny Dreadful, the committee discussed the career of Dr. Victor Frankenstein and turned their focus on how major natural events in 1816 influenced Mary Shelley's creation.

Our discussion segued to notable events that occurred one hundred years later (1916) that consequently put the impact of winter storm Jonas (2016) in a unique perspective. From January 22-24, 2016, Jonas produced up to three feet of snow in parts of the Mid-Atlantic and Northeastern United States. With all institutional operations suspended due to record snowfall [3], many students were housebound. Following the devastation of "Snowzilla," the course director encouraged SCREAM students 
to watch two "snowbound" films - The Shining (1980) and The Thing (1982) - in preparation for the next month's meeting. At the one-year anniversary of Jonas, this paper revisits the outcome of our discussion and conceptualizes three natural events (each 100 years apart) as inspiration for movies used to teach mental illness in the residents's REDRUM didactic.

\section{Discussion}

\section{6: Mount Tambora}

In April 1815, an Indonesian volcano erupted ejecting an estimated 25 cubic miles of debris into the stratosphere. The largest eruption in the last 10,000 years, a stratospheric cloud stretched around the earth leading to unprecedented climate change in parts of the world, including Europe. As depicted in the movie, Gothic (1986), Mary Godwin, Percy Shelley, Lord Byron, Claire Clairmont, and a young physician named John William Polidori rented a villa in Cologny, Switzerland in 1816. As a result of the seismic activity from Mount Tambora, an "incessant rain" [4] confined the group in the house for days. The company amused themselves by reading German ghost stories, prompting Byron to suggest they each write their own supernatural tale.

How Mount Tambora relates to psychiatry: Two hundred years ago on June 6, 1816, Mary Shelley had a waking dream of her creation: Frankenstein's monster. That same day, John Polidori conceived the vampire. The two most iconic monsters in literature were born on the same day and may be referenced to introduce personality theory and disorders to resident physicians. For example, a biographical analysis of Mary Shelley frames Frankenstein as a work of sublimation, with each character representing a major archetype of the author's collective unconscious (Table 1).

After reviewing personality theories of Carl Jung and others, residents are introduced to the personality disorders. Polidori's creation, the vampire, inspired Abraham "Bram" Stoker to write Dracula (1897). Count Dracula embodies a total disregard for and violation of others' rights. Plot summary and character analysis supporting the diagnosis of Antisocial Personality Disorder has been previously described [1].

\section{6: The Jersey Shore and Jaws}

Nearly 60 years before Peter Benchley's seminal novel, a real man-eater lurked in the waters of the Jersey shore. Between July 1 - July 12, 1916 [5], four people were killed and one injured by a rogue shark.

The 1916 shark attacks inspired Jaws, the tale of a white shark that terrorizes the small island community of Amity. A remake of Melville's Moby-Dick, Jaws caused many moviegoers to be afraid to enter the ocean in the summer of '75 and established the notion of the great white as nature's number one killing machine.
How Jaws relates to the field of psychiatry: First described by Walter Bradford Cannon, the hypothalamus influences various emotional responses including the fight-or-flight response. Building on Cannon's work, Jeffrey Alan Gray (1987) described a sequence of defensive responses that occur depending on one's proximity to danger:

a) Alert or vigilant immobility,

b) Escape,

c) Fighting,

d) Tonic immobility.

While the first three have been extensively studied in humans, tonic immobility has been primarily investigated in animal models.

Tonic immobility has been implicated in the diminishing numbers of great white sharks in recent decades [6]. There have been increasing reports of pods of killer whales hunting great whites utilizing tonic immobility by turning the shark on its dorsum thus inducing a natural state of paralysis. Tonic immobility is a limbic system function that serves as an animal model for dissociative-like symptoms experienced in the anxiety, trauma- and stressor-related disorders including Post-Traumatic Stress Disorder.

Much like a zombie apocalypse serving as a backdrop to the Romerian group dynamic [7], the imminent threat of the great white shark serves as the setting for the main characters in Jaws (1975) to interact. Sheriff Brody has a past psychiatric history significant for specific phobia, natural environment type (irrational fear of the water) and acts to mediate the conflict between Hooper and Quint, both of whom also have histories of prior trauma. Hooper had an experience with a thresher shark that "ate his boat" when he was young. Quint also shares his encounter with a thresher's tail when he shows Hooper a scar on his right leg. Right after, Brody points out a tattoo on Quint's left arm of the USS Indianapolis, marking Quint as a survivor of the greatest single loss of life at sea in the history of the US Navy. Quint relates the account of the ship that was torpedoed by a Japanese submarine. Of the 900 men who entered the water, only 317 survived; largely the result of the largest shark frenzy in recorded history.

Despite having past traumatic experiences, both Hooper and Quint chose careers at sea. This likely represents their employing denial and reaction formation, thus developing a counter phobic attitude [8] that results in them running towards (instead of avoiding) their fear. The final line of the movie, "I used to hate the water...I can't imagine why," illustrates the effect of flooding in extinguishing Brody's learned (avoidant) behavior. Of course - and ironically - Brody's "therapy" takes places when the Orca is flooded after having been rammed by the great fish; 
a reenactment of the rogue sperm whale that sank the Essex in 1820 (inspiration for Moby-Dick).

\section{6: Winter Storm Jonas and The Shining \&The Thing}

At the Amundsen-Scott South Pole station, most research personnel leave by the middle of February, leaving a few dozen "winter-overs" who keep the station functional through the months of Antarctic night. The winter personnel are isolated between mid-February and late October. After the last flight has left for the winter, an annual tradition is a double feature viewing of The Shining and The Thing.

\section{Synopsis: The Shining}

Jack Torrance, a writer and recovering alcoholic, takes a job as a "winter-over" at the isolated Overlook Hotel. His young son, Danny, possesses psychic abilities and is able to see things from the past and future such as the ghosts that haunt the Overlook. The film depicts the trials of the Torrance family, as the abject isolation of the snowbound hotel serves as the setting for the family's "descent into madness."

How The Shining relates to the field of psychiatry: The Shining is a film rich in subversive, psychiatric themes, with several interpretations rendered by authors, anthropologists, and historians [9] and serves as an opportunity to teach the Psychotic and Related Disorders. Hallucinations, delusions, disorganized and grossly catatonic behavior, and negative symptoms (affective flattening, apathy, and anhedonia) are all signs possessed by the patriarchal main character. While the general consensus is that The Shining explores themes related to psychosis, Stuart Ullman's disclosure of the 1970 tragedy of a former caretaker, Grady, "running amok" is foreshadowing of the origin of the family's psychotic break. Amok is a culturally (Malaysian) bound syndrome hallmarked by episodes of sudden mass assault following a period of brooding. A brief examination of the film reveals two themes that allow for the formulation of another culturally bound syndrome that explains the behavior of the Torrance family.

A pre-established delusion is identified in an individual: Prior to moving into the Overlook, Jack's son, Danny, has a terrifying premonition about the hotel that causes him to lose consciousness. During a medical evaluation, Wendy tells a visiting doctor that her son has an imaginary friend called "Tony" whose emergence coincided with Danny going to nursery school around the time Jack dislocated Danny's shoulder (following a binge episode). While the physician reassures Wendy that Danny's imaginary friend is "just a phase," there's reason to believe Tony is a sign of an underlying mental disorder and therefore is not developmentally appropriate. While posttraumatic stress disorder (PTSD) is a provisional diagnosis, two scenes are critical to the formulation of a differential diagnosis. First, Ullman tells Jack that the hotel is built on the site of a 1907 Native American burial ground. Next, a precocious Danny joins the discussion about the Donner party on the way to the Overlook. The ill-fated settlers had to resort to cannibalism after their wagon train was trapped by a heavy snowfall through the Sierra Nevada.

Taken together, we can conclude that Danny is afflicted with Wendigo psychosis; a culturally bound syndrome that affects people who think about cannibalism. Originally afflicting individuals of the Algonquin tribe, the syndrome preserves cultural taboos by reinforcing the prohibition against cannibalism. Danny's taking part in the adult discussion about the Donner party constitutes a significant boundary violation and results in his becoming possessed by the malevolent cannibalistic spirit.

A delusion develops in the context of a close relationship with another person that is similar in content to that of the person who already has the established delusion: Jack wanders into the Gold Room where a ghostly bartender named Lloyd serves him bourbon on the rocks. Meanwhile, Danny's curiosity gets the best of him when he wanders into Room 237 despite the omen not to enter. When Danny returns from Room 237, he is visibly traumatized, causing Wendy to think that Jack is abusing Danny again. Wendy shows up in the Gold Room and informs Jack that Danny told her a "crazy woman in one of the rooms" was responsible for his injuries.

Jack investigates Room 237 and has an experience similar in content to Danny's. Specifically, a mysterious female seduces Jack, but then turns into a symbolic manifestation of the wicked woman from Hansel and Gretel (who lured children like Danny with candy before transforming into a witch). The Hansel and Gretel fairy tale was foreshadowed when:

a) Danny brought up the topic of cannibalism

b) Wendy first met Dick Hallorann and said she felt the need to put down breadcrumbs in order to find her way around the Overlook.

Upon returning from Room 237, Jack casts an image in the mirror when entering the suite. He tells Wendy he found nothing, explaining that Danny's bruises were self-inflicted, "I think he did it to himself" [10]. Faced with this reality, Danny becomes acutely psychotic as evidenced by his "shining" (grossly catatonic behavior) into his parents' conversation. This further establishes that Danny is the proband case of psychosis. Danny's psychotic episode is followed by Jack's exacerbation (transmission) as evidenced by his becoming verbally abusive (disorganized behavior) towards Wendy. As he storms out of the suite, he casts no reflection in the mirror, having truly lost "his soul/who he is."

In summary, The Shining is a case study of Shared Psychotic Disorder (SPD). Also referred to as folie à deux, SPD is a rare psychotic disorder usually found in long-term relationships with close emotional ties. 


\section{Synopsis: The Thing}

Based on John W. Campbell, Jr.'s novella, Who Goes There?, the movie is about a parasitic, extraterrestrial life form that assimilates organisms at the molecular level, thus allowing it to phenotypically mimic its host.

Set in Antarctica, The Thing begins with a Norwegian helicopter pursuing an Alaskan malamute to an American research station. When the last surviving Norwegian is shot and killed, the Americans go to the Norwegian base only to find it burned to the ground. MacReady and the crew learn that the Malamute was alien but before they could kill it, the thing begins to assimilate the other dogs and members of the research team.

Considered by John Carpenter to be the first part of an apocalyptic trilogy along with Prince of Darkness and In the Mouth of Madness, The Thing pays homage to Dracula, depicting the trials of MacReady (modern day Van Helsing), who leads his team as they try to capture and kill the inhuman scourge before it can hibernate and move beyond the continent.

How the Thing relates to the field of psychiatry: We discover the goal of the thing is to hibernate or sleep, thus introducing the notion of the dyssomnias; sleep abnormalities in the amount, quality, or timing of sleep involving disruptions in mechanisms generating sleep-wake states. One dyssomnia, Non-24 Hour Sleep-Wake Type (a Circadian Rhythm SleepWake Disorder), is characterized by abnormal synchronization between the 24-hour light-dark cycle and the endogenous circadian rhythm. Given that:

a) The setting of the film is the Antarctic night,

b) The alien's circadian rhythm is longer than 24 hours [11],

c) The alien needs to hibernate,

The Thing may be viewed as an exercise in the Circadian Rhythm Sleep-Wake Disorders.

\section{Conclusions}

At our medical school, we have created a novel resident didactic where psychopathology is taught through the horror film genre. The main objective of REDRUM is to enhance learning through creative discussion of examples of psychopathology that come from film and literature. REDRUM is updated annually by a steering committee comprised of medical students who look at the historical context of movies that serve a metaphorical role in the depiction of mental illness. Beginning in June, 1816, three sets of natural events, each occurring 100 years apart, have influenced the creation of literary works related to mental illness. These seemingly random events including the eruption of Mount Tambora (1816), shark attacks down the Jersey shore (1916), and devastation of winter storm (2016) can be tied together to create a didactic to teach psychopathology (Table 1). Such creative didactics are essential for residents to apply, analyze, synthesize, and evaluate information [12].
Another benefit of engaging students with innovative didactics to teach psychopathology is capturing the attention of the $95 \%$ of students [2] who choose to pursue careers outside of Psychiatry. Only when future surgeons, internists, and obstetricians recognize the $18.6 \%$ of co-occurring psychiatric conditions [13] and 16\% incidence of substance use disorders [14] in their patients will the stigma of mental illness be addressed.

Table 1: Topics in Mental Health and the Stories that Inspired Them.

\begin{tabular}{|c|c|c|}
\hline \multicolumn{3}{|c|}{ Topics in Mental Health and the Stories that Inspired Them } \\
\hline Topic & Film/Novel & Summary \\
\hline Personality Theory & $\begin{array}{l}\text { Mary Shelley's } \\
\text { Frankenstein }\end{array}$ & $\begin{array}{l}\text { Shelley's characters } \\
\text { represent aspects of } \\
\text { the Jungian collective } \\
\text { unconscious }\end{array}$ \\
\hline $\begin{array}{l}\text { Personality } \\
\text { Disorders }\end{array}$ & $\begin{array}{c}\text { Bram Stoker's } \\
\text { Dracula }\end{array}$ & $\begin{array}{l}\text { Inspiration for Stoker's } \\
\text { eponymous antagonist } \\
\text { is from a non-fictional } \\
\text { biography of Antisocial } \\
\text { Personality Disorder }\end{array}$ \\
\hline Anxiety Disorders & Jaws & $\begin{array}{l}\text { Tonic immobilization of } \\
\text { the white shark serves } \\
\text { as an animal model for } \\
\text { dissociation seen in } \\
\text { anxiety disorders }\end{array}$ \\
\hline Psychotic Disorders & The Shining & $\begin{array}{c}\text { Jack Torrence } \\
\text { demonstrates psychotic } \\
\text { symptoms in the context } \\
\text { of his son's delusion upon } \\
\text { assuming the position of } \\
\text { caretaker at the Overlook } \\
\text { Hotel }\end{array}$ \\
\hline Sleep Disorders & The Thing & $\begin{array}{l}\text { Researchers of a remote } \\
\text { Antarctic post try to track } \\
\text { down an extraterrestrial } \\
\text { life form before it } \\
\text { hibernates, introducing } \\
\text { insomnia and other Sleep- } \\
\text { Wake Disorders }\end{array}$ \\
\hline
\end{tabular}

\section{References}

1. Tobia A, Draschil T, Sportelli D, Katsamanis M, Rosenberg S, et al (2013) The Horror!: A Creative Framework to Teach Psychopathology Via Metaphorical Analyses of Horror Films, Acad Psychiatry 37(2): 131-136.

2. Results and Data: 2015 Main Residency Match; Association of American Medical Colleges, 2015.

3. National Weather Service Eastern Region [NWSEastern] (January 24, 2016). "Final snowfall map \& totals" from the January 22-23, 2016 blizzard.

4. Johnson D (1991) Introduction: Frankenstein, By Mary Shelley, 1831, 3rd Edition. New York, Bantam Books.

5. Cindy E (2013) The Matawan Man-eater: The Real New Jersey 'Jaws' of 1916. Weird NJ.

6. Andrew C Revkin (2003) Atlantic Sharks Found in Rapid Decline. The New York Times. 
7. Jovanka Vuckovic, George A Romero (2011) Zombies!: An illustrated history of the undead. St. Martin's Griffin.

8. Ken Wilber (2000) Sex, Ecology, Spirituality. Shambhala.

9. Room 237 (2012) Director Rodney Ascher. IFC Films.

10. The Shining. Director Stanley Kubrick. The Producer Circle Company; Peregrine Productions, 1980.
11. D. Aaron Schweighardt (1982) The Thing: John Carpenter. Perf. Universal Pictures.

12. Eileen Lynd-Balta (2006) Using literature and innovative assessments to ignite interest and cultivate critical thinking skills in an undergraduate neuroscience course. CBE Life Sci Educ 5(2): 167-174.

13. The National Institute of Mental Health, 2012.

14. The World Health Organization, 2004.

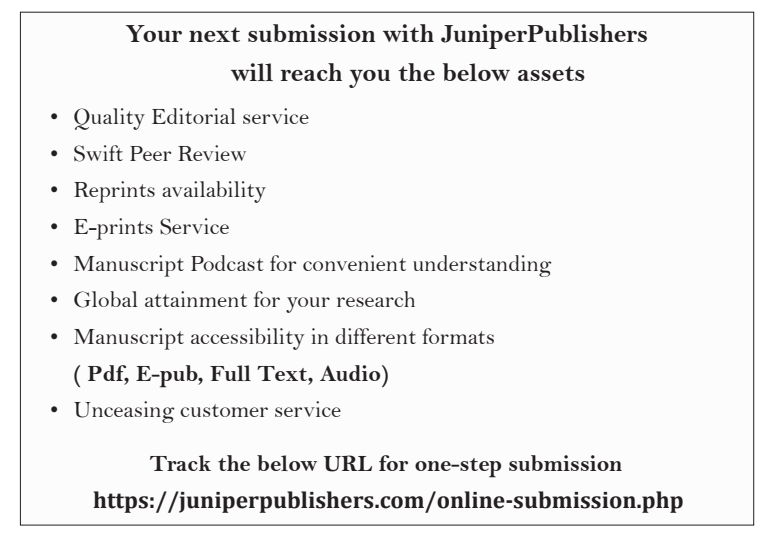

